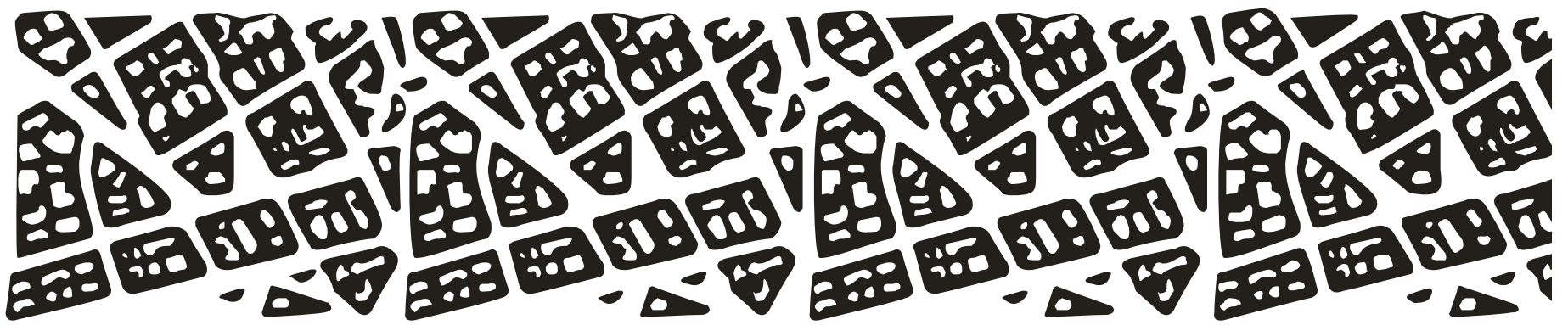

\title{
Geografia da destruição em Conversación al Sur
}

\author{
Susan Aparecida de \\ Oliveira
}

\section{Resumo}

O presente artigo sobre Conversación al Sur (1981) de Marta Traba, procura localizar a constituição do Sur como um espaço labiríntico e opaco que se vai formando em Buenos Aires e Montevidéu, tanto pela impossibilidade da manutenção das experiências de sociabilidade urbana como em razão da política do esquecimento estabelecida pelos procedimentos das ditaduras militares.

Palavras-chave: memória; ditadura; Sur; Buenos Aires; Montevidéu.

\section{Abstract}

The present article, about Conversacion al Sur (1981) by Marta Traba, aims to localize the constitution of the Sur as a labyrinthine and opaque space, that is being formed in Buenos Aires and Montevideo, through the impossibility of the maintenance of the urban sociability experiences due to the forgetfulness policy settled by the procedures of the military dictatorships.

Keywords: Memory; dictatorship; Sur; Buenos Aires; Montevideo

\footnotetext{
10 artigo que segue parte de algumas questões apontadas anteriormente por mim, em comunicação oral, durante o Seminário Internacional Fazendo Gênero 7 (2006), na qual o enfoque da discussão visava fundamentalmente a questão do gênero e da memória.
} 
"La ciudad le empezaba a pesar sobre el alma y recían los presentimientos (...) Nunca una ciudad más impecablemente triste."

(Conversación al Sur, p. 52,66)

Conversación al Sur (1981), da escritora argentina Marta Traba, é uma narrativa que, dentro dos seus vários desdobramentos memorialísticos e psicológicos, traça uma inquietante impressão das cidades de Buenos Aires e Montevidéu e da fragilidade das sociabilidades urbanas durante os anos de vigência das ditaduras militares na América Latina, destacadamente aqueles vividos na Argentina entre 1976 e 1983, no Uruguai, de 1973 a 1985, e no Chile, de 1973 a 1990.

O ano de 1973 é emblemático para o entendimento do conceito metanarrativo de Sur que a autora engendra, fundamentalmente pela ligação que faz entre Buenos Aires e Montevidéu, incluindo também referências a Santiago que, nesse mesmo ano, deixa de existir no imaginário do exílio para incluir-se nas experiências de horror do continente latino-americano:

Lo que nos resultaba increíble es que nosotros fuéramos la ciudad, nosotros el gobierno, nosotros la gente. Valía apena hacerse muerto para esto. Ahora que lo pienso, me parece imposible que no previéramos cuántos nos miraban con odio, espiando y esperando el momento de su revancha. ${ }^{2}$

A narrativa tem como fio condutor os relatos das violências vividas e testemunhadas por duas personagens, Irene e Dolores, cujo trânsito entre Buenos Aires e Montevidéu acaba por esboçar uma tensa cartografia em que a contiguidade entre as duas cidades emerge da lógica massificadora que se impõe, dito nos termos de Walter Benjamin, pelo empobrecimento da experiência. ${ }^{3} \mathrm{O}$ esvaziamento das relações humanas é colocado em paralelo com o crescimento do mesmo medo, em toda parte, decorrente dos métodos policiais aplicados em uma pavorosa repetição de procedimentos. A personagem Irene, conhecida atriz argentina, presa em uma delegacia de Montevidéu quando esteve na cidade, declara: "sentí que las cosas se recomponíam dentro de una nueva lógica" ${ }^{4}$ e lembra-se da parede detrás do comissário de polícia: "miraba el mapa del Uruguay lleno de cagadas de moscas. O serían ciudades?". ${ }^{5}$ A opacidade do mapa ou, por outro lado, a inutilidade do seu significado diante do impossível deslocamento remete à perda tanto da liberdade quanto da própria identidade: "Fuera quien fuera, yo no existia para ellos. Mejor dicho: ellos decretaban quién podía existir y quien no.(...) Yo era tan real como el mapa del Uruguay.. ${ }^{6}$ O mesmo sentimento e a mesma lógica de anulação se repetem quando Irene, após ser extraditada para Buenos Aires, chega ao destino, tendo que lá "entrar a una oficina igual a la otra, encontrarme al mismo jefe detrás del mismo escritorio y mirar fijo, ahora, el mapa de la Republica Argentina.".

\footnotetext{
TRABA, Marta. Conversación al Sur. México:Siglo Veinteuno Editores, 1981, p.140.

BENJAMIN, Walter. Magia e Técnica, Arte e Política. Tradução Sérgio Paulo Rouanet. São Paulo: Brasiliense, 1985 p.118. 
As duas cidades vão, assim, sendo unidas pelas tramas de um tecido indiferenciador produzido dentro de uma minuciosa operação de destruição de significados que não se vincula somente às investigações policiais, mas atinge as relações sociais e familiares e são reiteradamente inscritas nas ruas desertas, nas vitrines vazias, no risco de tomar um ônibus e dobrar as esquinas, no medo de entrar em casa e, uma vez nela, não poder abrir as cortinas; no susto ao ouvir a campainha ou o telefone.

$\mathrm{Na}$ criação da labiríntica Buenos-Aires-Montevidéu é necessário esquecer nomes e endereços, perder referências e mudar caminhos, o que não elimina, de modo algum, a perversa facilidade que há em "desaparecer" na malha das ruas desertas "sem saída” e repletas de armadilhas. Irene e Dolores apercebem-se, então, sobreviventes e, paradoxalmente, desconfiam e estranham a própria sobrevivência. Por isso, o medo, a impotência e a culpa passam a ser os sentimentos estruturantes de uma rotina de simulacros e autoanulação. Em Conversación al Sur tomamos contato com uma espécie de "memória impedida", pela qual atitudes esquecidiças são compulsivamente repetidas de tal modo que impedem o ato de lembrar. ${ }^{8}$

Nesse redemoinho, Irene, a atriz, comporta-se diante de Dolores como tal, interpretando o seu próprio papel, medindo a sua atuação pelas reações da amiga, tentando a todo custo manipular a sua imaginação com medo menos dela (Dolores) do que de si mesma. A teatralidade como autoanulação revela-se desde o início quando Dolores chega à casa de Irene, após cinco anos de afastamento entre as duas amigas. Irene a convida a entrar e pergunta se ela quer um café, "para enseguida, sin esperar respuesta, dirigirse hacia la cocina desde donde será más fácil, por lo menos siempre es así en el teatro, iniciar una conversación con preguntas tiradas desde lejos, al, que pueden contestarse o no contestarse.". ${ }^{9}$ Os movimentos corporais de Irene são estudados por ela como se pudesse, com eles, iludir a sua interlocutora (ou seria a si mesma?), tentando pensar que é no seu corpo e nos seus gestos que repousa a atenção de Dolores. Irene lança-se num jogo de sedução manejando as regras do contato para tornar-se tão superficial como impenetrável ao olhar da outra. Envolvida no seu simulacro de conversa e pelas estratégias do próprio encobrimento, Irene "esquecera" o nome de Dolores porque "el nombre recuerda todos los horrores conocidos y que de ninguna manera revolverá." Ela termina o café: "El água sube em la cafetera, y borbotea con fuerza. A qué diablos viene a meterse justo ahora que ella está defendiéndose de la memoria?". ${ }^{10}$

As preocupações de Irene com seu corpo e sua atuação transferem-se para a sua casa. O que Dolores estaria pensando sobre o excesso de coisas que ela guarda na sala ou no banheiro? O que pensa sobre a vista do seu apartamento? Ela divaga sobre o campo de visão de Dolores enquanto analisa o corpo magro, as mãos suadas dentro dos bolsos, o silêncio nervoso e os movimentos da amiga. Contudo, Irene cede, aos poucos, a desencadear da memória que a retira do seu delírio fetichista - absorvida pelos corpos e pelas coisas - para os acontecimentos significativos que lhe irrompem dolorosamente, desde a noite fatídica em Montevidéu, depois do teatro, depois da festa,

8 RICOEUR,Paul. A memória, a bistória, o esquecimento. Tradução Alain François (et. al.). Campinas: Editora da UNICAMP, 2007, p.452. A ideia de memória impedida é tomada por Ricoeur, segundo ele, a Freud, a partir dos textos "Luto e melancolia" e "Rememoração, repetição, perlaboração.".

9 TRABA,Marta. Ibidem, p.8.

10 TRABA, Marta. Ibidem, p.9. 
depois do enterro de um jovem morto pela polícia.

Trata-se, para as duas personagens, de um jogo de memórias em que ambas se precipitam, completando lacunas deixadas pela falha de percepção de uma e outra, escondendo ou colhendo indícios de fatos e nomes, mas cúmplices em busca do desvendamento da cena traumática original, daquele ponto onde tudo - o que, de certo modo, já era esperado - se precipitou. Irene retoma, então, a cena na festa de Luisa em Montevidéu como esse momento originário em que, com a chegada da polícia e a prisão delas(es), a vida de todos os presentes ficaria definitivamente à deriva. Esse momento significa a marca na qual Irene tateia insistentemente o limite entre o real e $o$ imaginário:"Todo lo demás ocurrido en ese dia, en cambio, pasó a la imprecisa movilidad de los recuerdos. Menos de dos dias en la ciudad se desmenuzaron en tal cantidad de variables que ya hubiera sido imposible separar lo real de lo imaginário."

No entanto, a festa marca tão somente um dos pontos de confluência de trajetórias só aparentemente desconectadas - das duas amigas e de vários outros companheiros - e cuja cumplicidade clandestina selava um destino comum. Para Dolores, "fue a partir de la noche que nos agarraron a todos en su casa, que comenzaron los viajes a Buenos Aires y que contacté con el grupo de Andrés.". ${ }^{12}$ Sobressai da narrativa de Traba a ideia de que não são apenas os contextos de enunciação das duas mulheres que se articulam, se sobrepõem e se chocam, mas que muitos outros contextos e diálogos vão emergindo do abismo em que foram lançados e do qual outras personagens "desaparecidas" vão retornando e recompondo os fragmentos que faltam na recuperação, cada vez mais complexa, da cena originária. Na visão de Irene: "No conversamos, excavamos. Si al menos supiera lo que estamos buscando!"13

$\mathrm{Na}$ tentativa de abarcar o que de fato aconteceu, ou seja, o ponto de origem de toda a experiência traumática, as personagens vão, pela conversa, tentando ampliar o espectro de significados, mas, como afirma Maria Rita Kehl, a fala como campo simbólico nunca pode alcançar o "real todo", ficando sempre algo no escuro da representação. ${ }^{14}$ Vale reiterar que é pela fala o quanto à memória é sempre necessário algum esquecimento:

Volviendo a Luisa, sabes que jamás he vuelto a pasar por la plaza Zabala de la falta que me hace? No me la imagino en Lyon.Ya verás que aparece por acá en cualquier momento. Aunque con los que se fueran pasa una cosa muy rara, viste? Al principio escriben seguido, muertos de nostalgia, y poco a poco van despegando. Eso sería lógico, pero no es sólo eso; es como si se volvieran otra gente, alguien que nunca estuvo aquí. ${ }^{15}$

A percepção de Dolores sobre Luisa remete à questão de que a memória $\mathrm{e}$ os lugares, de alguma forma, estão ligados. No entanto, o juízo de Dolores se reflete

11 Idem,Ibidem, p.26-27.

12 TRABA, Marta. Ibidem, p.104. Trata-se do grupo político de Andrés do qual Dolores começa a fazer parte após o seu grupo montevideano ser desmontado pelas ações policiais, tendo sido quase todos mortos.

13 Idem, ibidem, p. 46.

14 KEHL, Maria Rita. "O sexo, a morte, a mãe, o mal." In: NESTROVSKI, Arthur e SELIGMAN-SILVA, Márcio (Orgs). Catástrofe e Representação. São Paulo: Escuta, p.138.

15 TRABA, Marta. Ibidem, p.54. Dolores refere-se ao exílio de Luisa em Paris. 
na definição de Pierre Nora, ${ }^{16}$ pois, segundo ele, o que os lugares marcam, de fato, é a falta da memória espontânea, ativa e pessoal, de tal modo que frequentamos não os lugares de memória, mas o que eles representam da ausência e dos restos da memória impedida.

Os lugares de memória criam o campo de signos que sustentam o autoritarismo de uma memória oficial mesmo sem a presença ostensiva da repressão armada. No entanto, a ambivalência lhes é inerente porque são lugares que ritualizam a memória ativa e estão, por isso, investidos de uma aura simbólica ${ }^{17}$ que transgride a interdição da memória. Tal é a Plaza de Mayo, nas constatações de Irene.

Miró y miró buscando qué había de raro en una plaza provinciana que se conocía de memoria. Fue pasando del Cabildo a la Catedral, volvió atrás. La inefable casa rosada le cerraba la posibilidad de ver el río. Cuándo echarían abajo ese edefesio? Todo estaba igual que siempre, feo, chato, pelado. Y de golpe se dio cuenta; en la plaza no había nadie, aparte de los grupos de mujeres que llegaban para la manifestación.(...) Así que éstas eran las locas de la Plaza de Mayo? Increíble tal cantidad de mujeres y tanto silencio; sólo se oían pasos rápidos, saludos furtivos.(...) La casa rosada parecía un escenario irreal, con las ventanas cerradas por espesos cortinajes. Tampoco los granaderos estaban montando guardia en la puerta. ${ }^{18}$

Nas quintas-feiras, a invisibilidade do poder era a prova cabal da sua atuação. Nesse dia, "se borraba del mapa la Plaza de Mayo durante las dos o tres horas de las habituales manifestaciones de los jueves (...)" e era pela ausência dos guardas que se criava uma obediência ainda mais brutal. Irene conclui que "el sistema era ignorarlas; ignorar la existencia de la plaza y das locas que pataleaban. A ese grado de refinamiento habían llegado? Y por qué no, si al mismo nivel estaban en cuanto a torturas y desapariciones. Un país dessarollado hace bien las cosas." ${ }^{\prime 19}$

A perspectiva aguda e irônica que revela Irene ao referir-se ao "país desenvolvido", demonstra a criticidade da própria autora que repercute também no termo Sur como equivalente dessa crítica que tem tanto de política como de epistêmica. O "país desenvolvido", assim como as cidades de Buenos Aires e Montevidéu, não existem mais como particularidades, dando lugar a um todo cuja lógica "pressentida" por Irene só pode ser apreendida "em seu refinamento" como lastro comum a partir das experiências particulares. A percepção crítica do esvaziamento das relações de sociabilidade aparece na (auto) ironia com que Irene reveste de "equívoco" o próprio estranhamento diante do fato de que, fora as loucas, ninguém mais na cidade sequer cruzava a praça durante a manifestação. Quando as mães se afastaram, Irene observou:

Ahora la plaza entera estaba ocupada por ratas tranquilas o apresuradas. Ratas y más ratas salían y entraban de las bocacalles. [...] Miré hacia la catedral y vi las escalinatas llenas de ratas. Pero

\footnotetext{
16 NORA, Pierre. Entre a memória e a história: a problemática dos lugares. In: Revista Projeto História. PUC-SP, São Paulo, n.10, 1993, p. 15.

17 Idem, Ibidem, p. 13-21.

18 TRABA, Marta. Ibidem, p.85, 87.

19 Idem, Ibidem, p.87.
} 
eran realmente ratas? (...) Miré hacia la casa rosada, dos granaderos montaban guardia. ${ }^{20}$ (grifos meus)

Em Conversación al Sur, a Plaza de Mayo, a Plaza Zavala e outros tantos pontos das cidades de Buenos Aires e Montevidéu não são apenas lugares físicos, mas signos da lógica de esvaziamento da afetividade e produção das ruínas da vida comum como experiência socialmente significativa. Essa lógica é ampliada pelo sentido de perda recíproca entre os que se foram e os que ficaram "esquecidos" na Buenos Aires-Montevidéu e imaginam uma melancólica unidade com os que pensavam estar, de algum modo - como Luisa na França e o filho de Dolores em Santiago - a salvo fora desse eixo. ${ }^{21}$ Marta Traba expõe, consequentemente, uma visão nada alentadora do exílio, pois na geografia explicitada na ideia de Sur estão tanto os que ficaram como os que se foram e as perdas das relações e das referências para todos eles são irrecuperáveis e nenhuma garantia há para a memória.

\section{Referências bibliográficas}

BENJAMIN, Walter. Magia e Técnica, Arte e Política. Tradução Sérgio Paulo Rouanet. São Paulo: Brasiliense, 1985.

KEHL, Maria Rita. O sexo, a morte, a mãe, o mal. In: NESTROVSKI, Arthur e SELIGMAN-SILVA, Márcio (Orgs). Catástrofe e Representação. São Paulo: Escuta, p.137-148.

NORA, Pierre. "Entre a memória e a história: a problemática dos lugares." In: Revista Projeto História. PUC-SP, São Paulo, n.10, 1993.

RICOEUR, Paul. A memória, a bistória, o esquecimento. Tradução Alain François (et. al.). Campinas: Editora da UNICAMP, 2007.

TRABA, Marta. Conversación al Sur. México:Siglo Veinteuno Editores, 1981.

20 TRABA, Marta. Ibidem, p.92.

21 O filho da personagem Irene, que fora para o Chile com a esposa para fugir da ditadura na Argentina, acaba sendo vitima da escalada feroz da violência que tornou inseparáveis, no ano de 1973, as experiências de horror da America Latina. 